\title{
Applying a Novel Fuzzy-PI Controller on the Model of Continuous Stirred Tank Reactor
}

\author{
A. M. Yazdani, M. A. Movahed, and S. Mahmoudzadeh
}

\begin{abstract}
Continuous Stirred Tank Reactor (CSTR) presents a significant role in the most of chemical process industries. The inherent nonlinear dynamic of CSTR results in various difficulties of stabilizing and controlling of the process. Likewise, functional changes with elapsing of the time and different disturbances associated with real environment are the other hints which must put into perspective. In this paper, a novel strategy based on the combination of fuzzy gain scheduling and a socio-political optimization algorithm, imperialist competitive algorithm, has been employed to design an intelligent Fuzzy-PI controller so that it surmounts the problem of system's parameter variation throughout the controlling of CSTR temperature. The controller has two inputs which are error and derivative of error and two outputs that are the proportional gain and integral gain. The controller is updated continuously to track the changes which are occurred in the system. To obtain the high performance control, imperialist competitive algorithm was employed to determine the optimum membership functions of the input and output variables. The performance of the proposed controller has been consider based on the Sum of the Square Error (SSE) and Integral Absolute Error(IAE) Criteria. In addition, conventional PI controller and classic online PI controller were applied to the system for the performance comparison. The results clearly indicate the robustness of Fuzzy-PI controller in dealing with uncertainties throughout the tracking of the reference signal. Fuzzy-PI controller also embodies an outstanding accuracy of tracking which leads to the least tracking error criterion.
\end{abstract}

Index Terms - Fuzzy-PI controller, Imperialist Competitive Algorithm (ICA), Gain Scheduling.

\section{INTRODUCTION}

CSTR is considered as an attractive and controversial subject due to its nonlinear dynamic behavior in the area of control engineering. There are various researches which have been tried to offer a control strategy so that the control objectives are satisfied properly [1]. Dependence of the conventional controllers on the linear and time varying characteristics cannot fulfill the objectives of the control when the plant parameters are changing with respect to the

Manuscript received March 27, 2011.This work was supported in part by UTM. Universiti Teknologi Malaysia, Department of Mechatronic and Robotic,Skudai ,Johor Bahru, Malaysia

A. M. Yazdani is with the Faculty of Electrical Engineering, Universiti Teknologi Malaysia, 81310 Skudai, Johor Malaysia; (e-mail: yazdani@fkegraduate.utm.my).

M. A. Movahed is with the Faculty of Electrical Engineering Universiti Teknologi Malaysia, 81310 Skudai, Johor Malaysia; (e-mail: ahamadi@fkegraduate.utm.my).

S. Mahmoudzadeh is with the Department of Computer Engineering, Islamic Azad University, Shabestar branch, Iran (e-mail: somaye_mahmoudzadeh@yahoo.com). time. Therefore, designing the controller which is less dependent on the crisp dynamic modeling of the system is a crucial task. In recent years, biological intelligent computations have been saliently used in the various areas of investigations [2]. Application of fuzzy logic, neural networks, and evolutionary algorithms in solving rigid problems particularly when dealing with uncertainties, result in a strong tendency toward this approaches [3]. Success of the fuzzy logic, which is based on the approximate reasoning instead of crisp modeling assumption, remarks the robustness of this method in real environment application [4]. It can also observe the practical implementation of fuzzy logic in fuzzy controller due to employ as an intelligent controller in real control application. Fuzzy logic controller emulates the behavior of the experts in controlling the system. Not needing the precise mathematical modeling cause more flexibility in dealing with complex nonlinear problem. However, enjoying the expert knowledge, construct the rule base of fuzzy controller. Strictly dependent to the expert knowledge, is one of the remarkable issues in designing the fuzzy controllers [5]. Several studies have been done in the past about the precise structure designation of fuzzy logic controller by different methods. Genetic algorithm based fuzzy controller is well known technique in this way [6].In this study, Fuzzy Gain Scheduling (FGS) method was employed to construct Fuzzy-PI controller so that the performance of the system control increases. In other words, FGS tries toward the online tuning of the PI parameters. Determining the precise structure for FGS, forms in an optimization problem. The optimal structure of FGS is determined through finding the membership function of the variables, using a novel global search strategy, called Imperialist Competitive Algorithm (ICA). Imperialist competitive algorithm is a new optimization algorithm which is inspired by imperialistic competition. It is a population based algorithm that, so called countries in population individuals, are of the two types: colonies and imperialists that all together form some empires. The basis of this evolutionary algorithm is Imperialistic competition among the empires. Throughout this algorithm, weak empires are eliminated and the powerful ones take the possession of their colonies. Finally, imperialistic competition converges so that one empire and its colonies are in the same position and have the same cost as the imperialist.

Application of this algorithm in some benchmark cost functions, presents its capability in various optimization problems. [7], [8]. In this study, ICA is employed to obtain the optimum membership function for inputs and outputs variables in fuzzy gain scheduling structure. Consequently, this approach forms in an intelligent Fuzzy-PI controller 
applied to the CSTR for high performance temperature control. In the following part of this paper, section II studies the mathematical description of CSTR. In Section III, gain scheduling technique and its applications is discussed. A brief introduction on ICA is presented in section IV and in the subsequent part the methodology based on ICA to constitute the Fuzzy-PI structure is offered. Section VI, argues the results of the simulation and in section VII, conclusion is presented.

\section{DYNAMIC MODEL OF CSTR}

Chemical reactions in a reactor are either exothermic or endothermic and therefore require that energy either be removed or added to the reactor for a constant temperature to be maintained. Fig. 1 illustrates the schematic of the CSTR process. In the proposed CSTR, an irreversible exothermic reaction takes place. The heat of the reaction is removed by a coolant medium that flows through a jacket around the reactor. A fluid stream A is fed to the reactor. A catalyst is placed inside the reactor. The fluid inside the reactor is perfectly mixed and sent out through the exit valve. The jacket surrounding the reactor also has feed and exit streams. The jacket is assumed to be perfectly mixed and at a lower temperature than the reactor [9], [10]. The mathematical model equations are obtained by a component mass balance (1) and energy balance principle (2) in the reactor.

$($ Accumulation of component Mass $)=($ component Mass $)$ in -

(component Mass)out + (generation of component Mass)

$($ Accumulation $\mathrm{U}+\mathrm{PE}+\mathrm{KE})=(\mathrm{H}+\mathrm{PE}+\mathrm{KE})_{\text {in }}$ $(\mathrm{H}+\mathrm{PE}+\mathrm{KE})_{\text {out }}+\mathrm{Q}-\mathrm{Ws}$

The mathematical model of CSTR is [11], [12], [13]:

$$
\begin{aligned}
& \frac{d c_{a}}{d t}=\left(\frac{F}{V}\right) \cdot\left(c a_{f}-c_{a}\right)-k_{0} \cdot \exp \left[\frac{E}{R \cdot(T+460)}\right] \cdot c_{a} \\
& \frac{d T}{d t}=\left(\frac{F}{V}\right) \cdot\left(T_{f}-T\right)-\frac{\Delta H}{\rho \cdot C_{p}} \cdot\left[k_{0} \cdot \exp \left[-\frac{E}{R \cdot(T+460)}\right] \cdot c_{a}\right] \\
& -\left(\frac{U \cdot A}{\rho \cdot C_{p} \cdot V}\right) \cdot\left(T-T_{j}\right)
\end{aligned}
$$

Where $\mathrm{Tj}$ is the jacket temperature as the input, while $\mathrm{Ca}$ and $\mathrm{T}$ are concentration and temperature of reagent as the outputs respectively. It should be noted that the objective is to control the temperature of tank by manipulating $\mathrm{Tj}$. All parameters are shown in table I.

\section{FUZZY GAIN SCHEDULING}

Gain-scheduling is a well-known technique of industrial control and it is employed when a plant is subject to large changes in its operating state. Large changes in the operating state lead to variations in the parameters of the liberalized models of the plant. It is remarkable that it is not possible therefore to design a controller to operate satisfactorily at one operating state and expect it to perform equally well elsewhere without re-tuning it. The performance of the system is degraded since the controller cannot track the changes in the operating states. Considerable effort has gone into developing controllers that can track the variations in plant parameters with a view to achieving invariant operation throughout the domain of operation of the plant. Adaptive controllers are one such approach, yet even these controllers do not always demonstrate satisfactory performance throughout the domain of operation of the plant and may, on occasion, lose control altogether. Robust controllers, another approach, also have their limitations since they must deal with system dynamics that vary over a wide range though using constant parameters only. Clearly this class of controllers can only operate satisfactorily over a limited domain [9], [10].

TABLE I. MATHEMATICAL MODEL PARAMETERS OF CSTR

\begin{tabular}{|l|l|l|}
\hline variables & values & Unit \\
\hline $\mathrm{Ca}$ & ------ & \multicolumn{1}{|c|}{$\mathrm{lbmol} / \mathrm{ft}^{3}$} \\
\hline $\mathrm{T}$ & -------- & of \\
\hline $\mathrm{Ea}$ & 32400 & $\mathrm{BTU} / \mathrm{lbmol}$ \\
\hline $\mathrm{K} 0$ & $\begin{array}{l}1.50 \mathrm{E}+1 \\
3\end{array}$ & $\mathrm{Hr}^{-1}$ \\
\hline$\Delta H$ & -45000 & $\mathrm{BTU} / \mathrm{lbmol}$ \\
\hline $\mathrm{U}$ & 75 & \\
\hline$\rho$ & 53.25 & $\mathrm{BTU} / \mathrm{ft}^{3}$ \\
\hline $\mathrm{R}$ & 1.987 & $\mathrm{BTU} / \mathrm{lbmol}-\mathrm{of}$ \\
\hline $\mathrm{V}$ & 750 & $\mathrm{ft}^{3}$ \\
\hline $\mathrm{F}$ & 3000 & $\mathrm{ft}^{3} / \mathrm{hr}^{3}$ \\
\hline $\mathrm{Ca}$ & 0.132 & $\mathrm{lbmol} / \mathrm{ft}^{3}$ \\
\hline $\mathrm{T}_{\mathrm{f}}$ & 60 & of $^{3}$ \\
\hline $\mathrm{A}$ & 1221 & $\mathrm{ft}^{2}$ \\
\hline
\end{tabular}

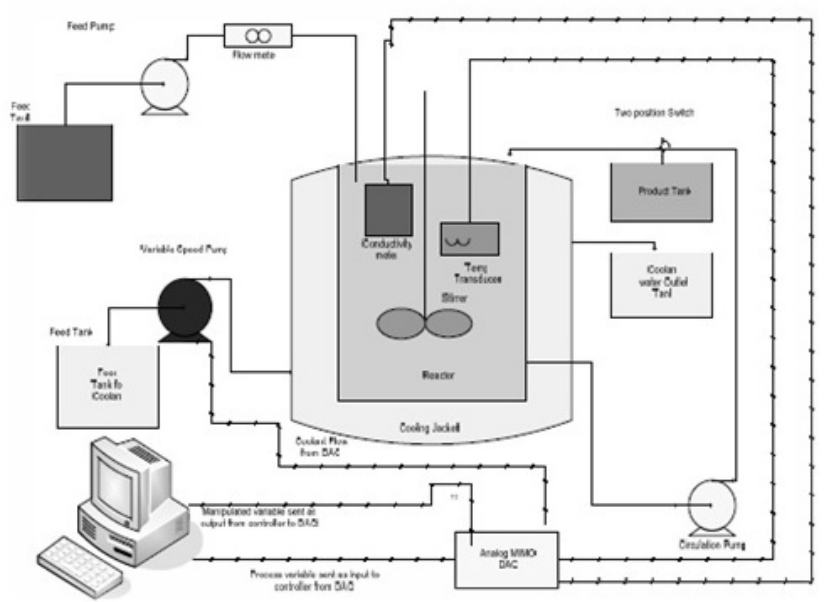

Fig.1 CSTR process

However, the solution suggested in this paper to overcome the difficulties of system's variations is gain scheduling approach which is described based on fuzzy logic concept. It means that a fuzzy construction is playing the role of the critic to on line tuning of the PI parameter, and entirely form an intelligent Fuzzy-PI controller.

Regarding the control signal based on the PI structure 
shown in (5):

$u_{p}(t)=k_{p} e(t)+k_{i} \int_{0}^{t} e(t) d t$

Where $\mathrm{KP}$, and $\mathrm{Ki}$ are proportional and integral gains respectively. FGS structure includes e $(\mathrm{t})$ and de(t) which are error and derivative of error as inputs and $\mathrm{Kp}, \mathrm{Ki}$ as outputs. The bound for the error is [-10 10] and for the derivative of error is [-192 56], illustrated in fig. 2, and 3, while the changes of KP is done in the bound of [lll 10 18] and for $\mathrm{Ki}$ these variations are in [50 73.48].The main role of FGS is online tuning of the proportional and integral gains based on the fuzzy computation. Fig. 4 shows the graphic representation of FGS structure.

The proposed structure makes decision to set the value of the KP, and Ki parameters automatically with respect to the time, based on the 9 rules determined by the expert. In table II, rules bases corresponding to the changes in $\mathrm{e}(\mathrm{t})$ and $\mathrm{de}(\mathrm{t})$ are depicted.

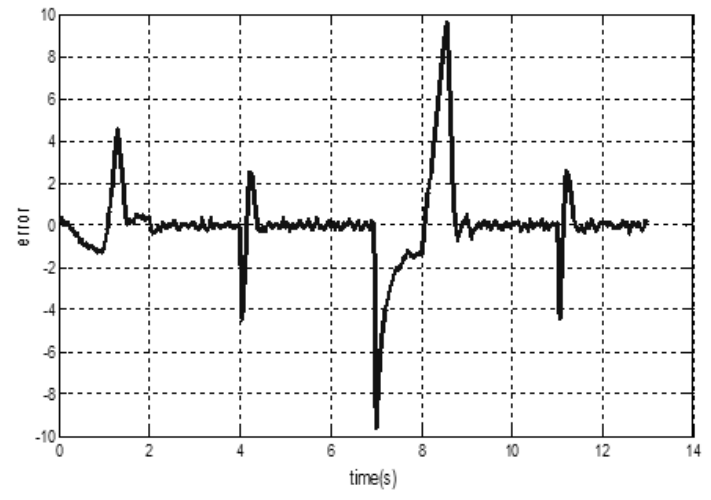

Fig. 2 Bound of the error variations

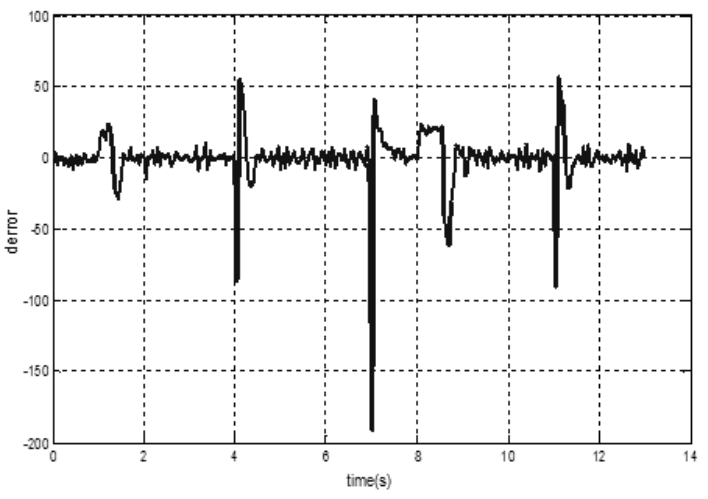

Fig. 3 Bound of the derivative of error variations

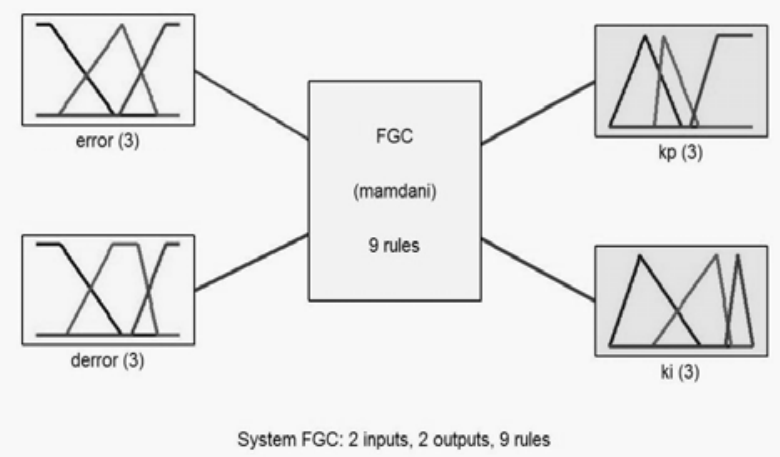

Fig. 4 Graphical representation of fuzzy gain scheduling structure
TABLE II. RULE BASE FOR FUZZY INFERENCE ENGINE

\begin{tabular}{|l|l|l|l|}
\hline derror & Negative & Zero & Positive \\
\hline Negative & Negative & Negative & Positive \\
\hline Zero & Negative & Zero & Positive \\
\hline Positive & Negative & Positive & Positive \\
\hline
\end{tabular}

However, appropriate response of the plant to the various set point signals is directly related to the value of the parameters $\mathrm{KP}$, and $\mathrm{Ki}$ which are determined by FGS. To satisfy this issue, a novel strategy is needed to design more accurate membership function of inputs and outputs fuzzy sets. This strategy is introduced in the form of optimization problem. A global search algorithm called ICA was employed to find the appropriate membership function partitions. In the next section, this problem is considered.

\section{BRIEF DESCRIPTION OF IMPERIALIST COMPETITIVE ALGORITHM}

Imperialist competitive algorithm was introduced first time by E.A.Gargary and C.Lucas in 2007 [7]. It is a global heuristic search method that uses imperialism and imperialistic competition process as a source of inspiration.

This algorithm starts with some initial countries. Some of the best countries are selected to be the imperialist states and all the other countries form the colonies of these imperialists. The colonies are divided among the mentioned imperialists based on their power. After dividing all colonies among imperialists and creating the initial empires, these colonies start moving toward their relevant imperialist state. This movement is a simple model of assimilation policy. The algorithm can be described in below flowchart [8].

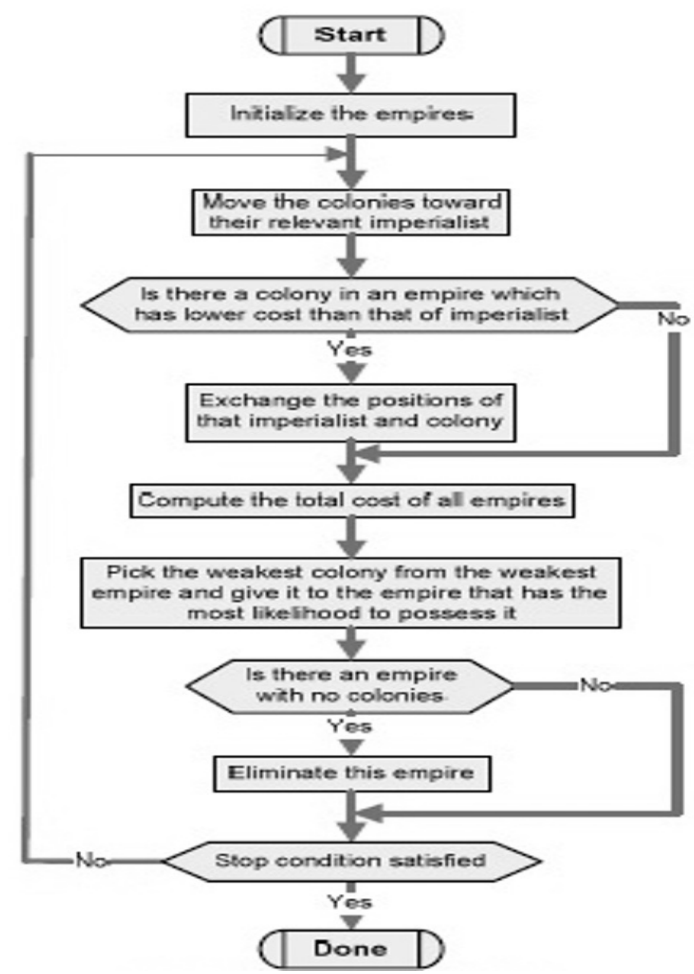

Fig. 5 Pseudo code for the ICA 
The movement of a colony towards the imperialist is shown in (6). Fig. 6 also illustrates this structure. In this movement, $\theta$ and $\mathrm{x}$ are random numbers with uniform distribution and $\mathrm{d}$ is the distance between colony and the imperialist.

$$
\begin{aligned}
& x \sim(0, \beta \times d) \\
& \theta \sim U(-\gamma, \gamma)
\end{aligned}
$$

Where $\beta$ and $\gamma$ are arbitrary numbers that modify the area that colonies randomly search around the imperialist. $\beta$ and $\gamma$ are 2 and 0.5 (rad), in our implementation, respectively. The total power of an empire depends on both the power of the imperialist country and the power of its colonies. This fact is modeled by defining the total power of an empire by the power of imperialist state plus a percentage of the mean power of its colonies. In imperialistic competition, all empires try to take possession of colonies of other empires and control them. This competition gradually brings about a decrease in the power of weak empires and an increase in the power of more powerful ones. This competition is modeled by just picking some (usually one) of the weakest colonies of the weakest empires and making a competition among all empires to possess these (this) colonies. Fig. 7 shows a big picture of the modeled imperialistic competition.

Based on their total power, in this competition, each of empires will have a likelihood of taking possession of the mentioned colonies. The more powerful an empire, the more likely it will possess these colonies. In other words these colonies will not be certainly possessed by the most powerful empires, but these empires will be more likely to possess them. Any empire that is not able to succeed in imperialist competition and cannot increase its power (or at least prevent decreasing its power) will be eliminated. The imperialistic competition will gradually result in an increase in the power of great empires and a decrease in the power of weaker ones.

Weak empires will gradually lose their power and ultimately they will collapse.

The movement of colonies toward their relevant imperialists along with competition among empires and also collapse mechanism will hopefully cause all the countries to converge to a state in which there exist just one empire in the world and all the other countries are its colonies. In this ideal new world colonies have the same position and power as the imperialist [7], [8]. To determine the optimum membership function, the algorithm is initialized by number of 120 countries and 10 empires. The revolution rate is equal to 0.5 and the number of selected iteration equal to 100 as well. The cost function is defined as Sum of Square Error (SSE). ICA offers the optimum membership function so that the SSE is minimized.

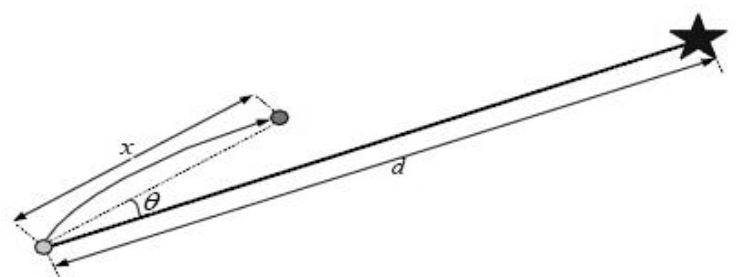

Fig. 6 Movement of colonies toward their relevant imperialist in a randomly deviated direction

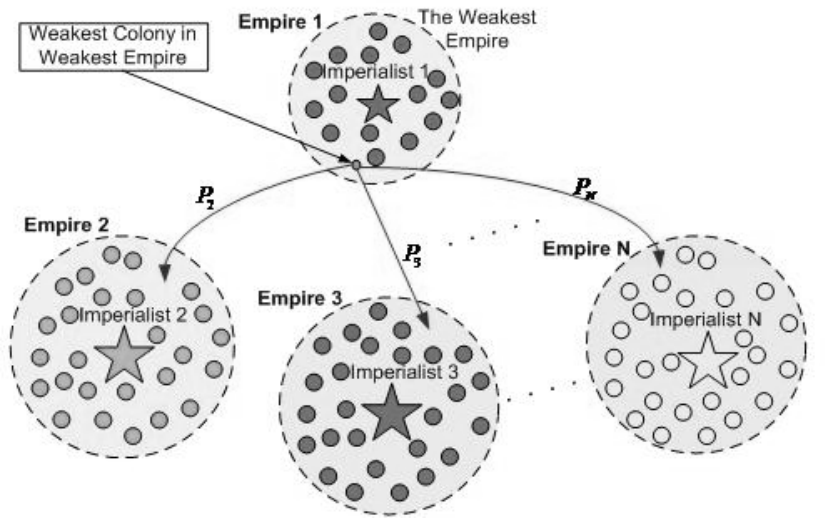

Fig. 7 Imperialistic competition: The more powerful an empire is, the more likely it will possess the weakest colony of weakest empire.

\section{ENHANCING THE PERFormanCE USING ICA}

In this part, imperialist competitive algorithm (ICA) is applied to the fuzzy gain scheduling model to find the optimum membership functions both in inputs and outputs. To address these concerns, the parameters of the membership functions are coded to form the array country [5] and a cost function is defined in such a way that the design criteria are satisfied through minimizing it.

Fig. 8, and 9 illustrate the typical membership functions of input variables error and derror in three relevant sets. Each set of the input membership function, comprises three parts, called Negative, Zero, and Positive .These sets in membership function of the first and second input can be specified by points $\mathrm{Pi}(1 \leq i \leq 15)$. Non-identical arranging the membership function's partitions results in more flexibility in designation.

The same procedure is done for the outputs. In fig. 10, and 11 the membership function of the outputs are coded in points $\operatorname{Pi}(16 \leq i \leq 29)$.

Therefore, the problem of finding the membership functions is related to the problem of determining 29 points. The 29 points are put together to form the array country.

Sum of square error was selected as the cost function. The best solution leads to minimize the performance criterion.

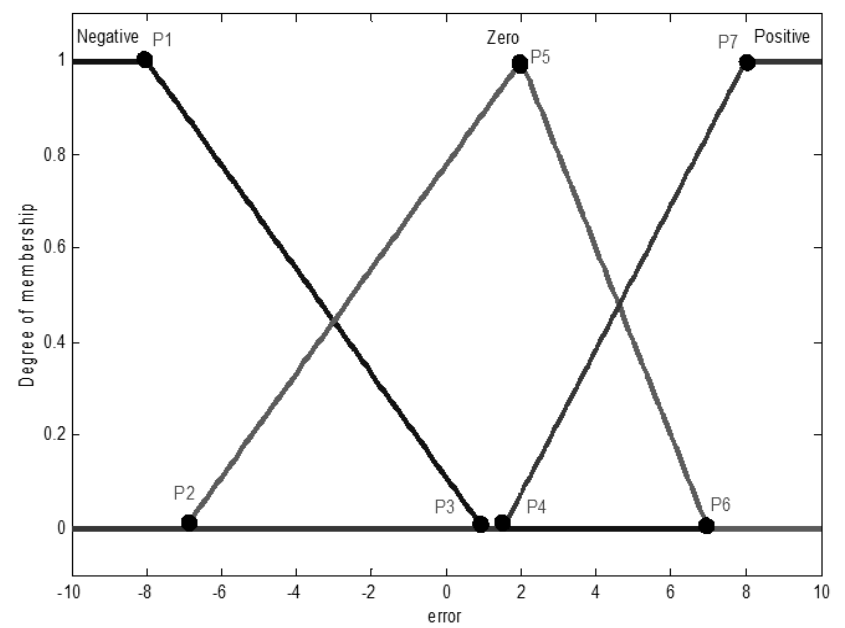

Fig. 8 Membership function of input variable error 


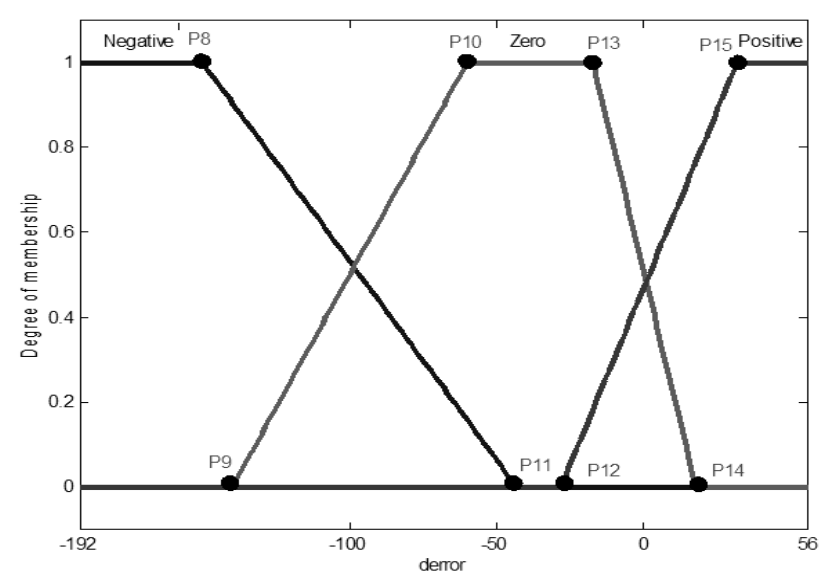

Fig. 9 Membership function of input variable derror

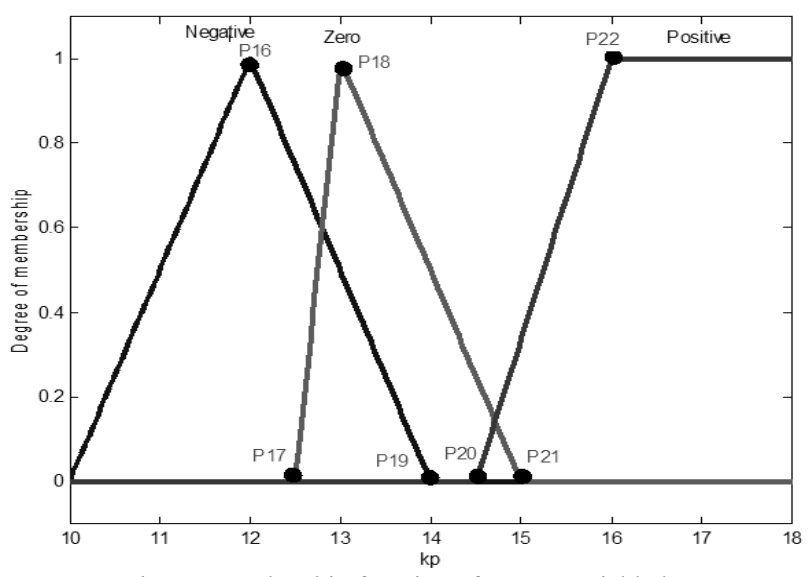

Fig. 10 Membership function of output variable kp

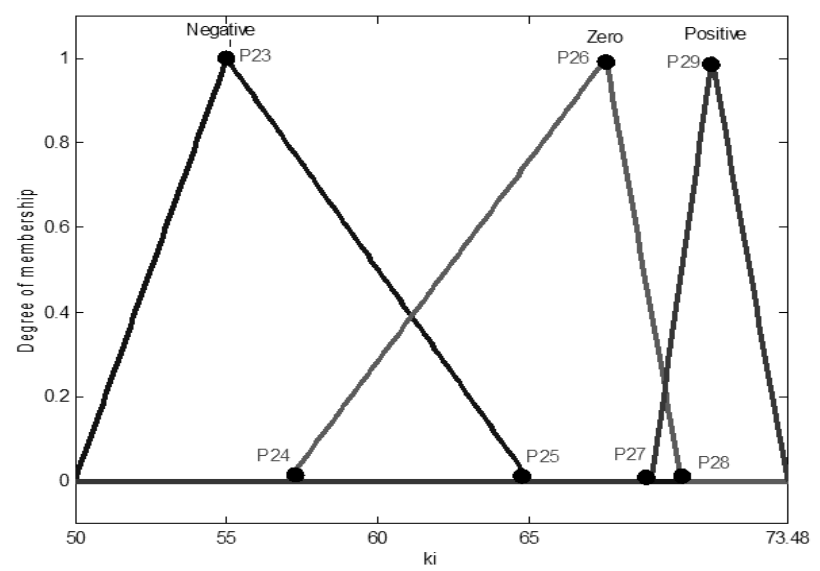

Fig. 11 Membership function of output variable ki

\section{RESULTS}

In this part the results of the problem of finding optimum partitions for membership functions of the inputs and outputs is offered. Coded parameters in the form of the points that construct the country array lead to the best solution. Furthermore this technique is a new strategy that can be compared by expert. In the fig. 12, and 13 modified membership functions of inputs, found by ICA, is illustrated.

In the same way, ICA is also offered the optimum membership functions for the two outputs variable which are indicated in fig. 14, and 15 .

Now, the prepared intelligent controller is applied to the plant to control the temperature of the CSTR. The criterion for evaluation of the performance of the proposed controller is SSE which must be minimized. Furthermore, IAE, which is indicated as the closeness of the response to the set point, is regarded as the second criterion. Table III, expresses a fair comparison between the performance of Fuzzy-PI and previous applied controller [14] to the process.

TABLE I. COMPARING THE RESULTS OF THREE DIFFERENT CONTROLLER

\begin{tabular}{|l|c|c|}
\hline \multicolumn{1}{|c|}{ MODEL } & SSE & IAE \\
\hline Fuzzy-PI controller & 21.7 & 9.935 \\
\hline Self-adaptive PI controller & 28.86 & 9.987 \\
\hline Fixed gain PI controller & 43.11 & 10.595 \\
\hline
\end{tabular}

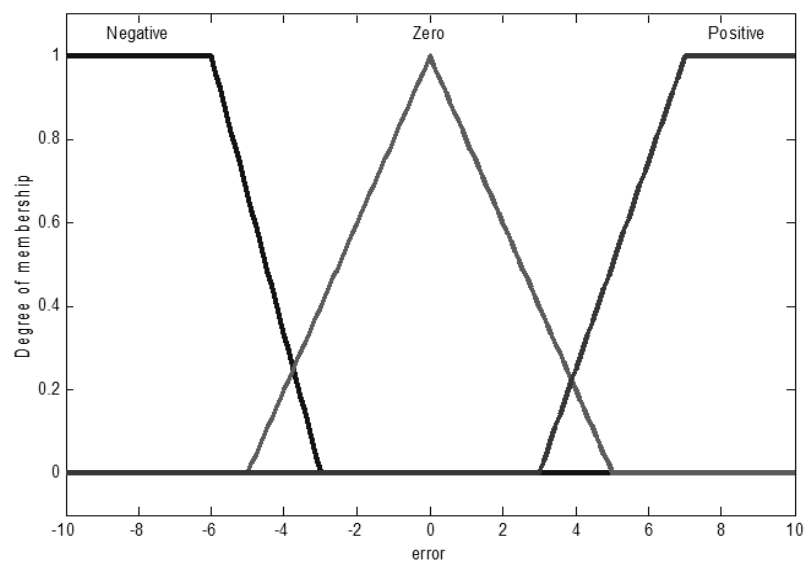

Fig. 12 Modified membership function of input variable error by ICA

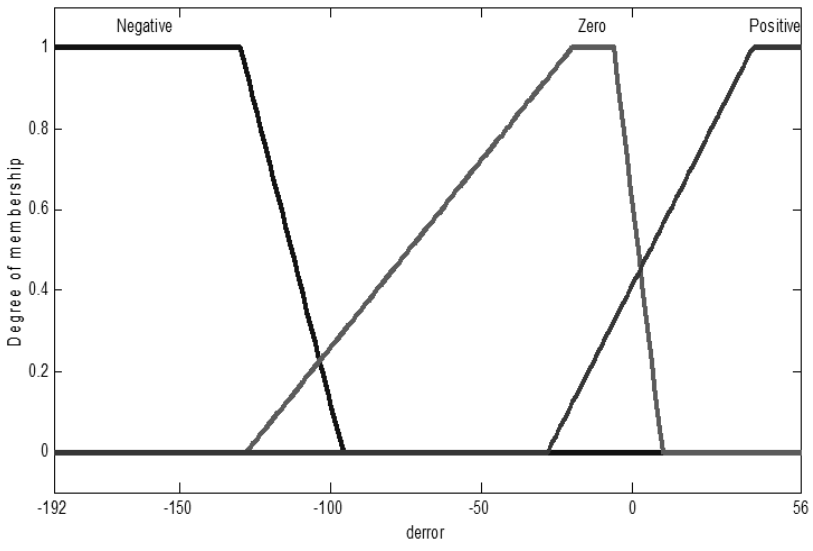

Fig. 13 Modified membership function of input variable derror by ICA

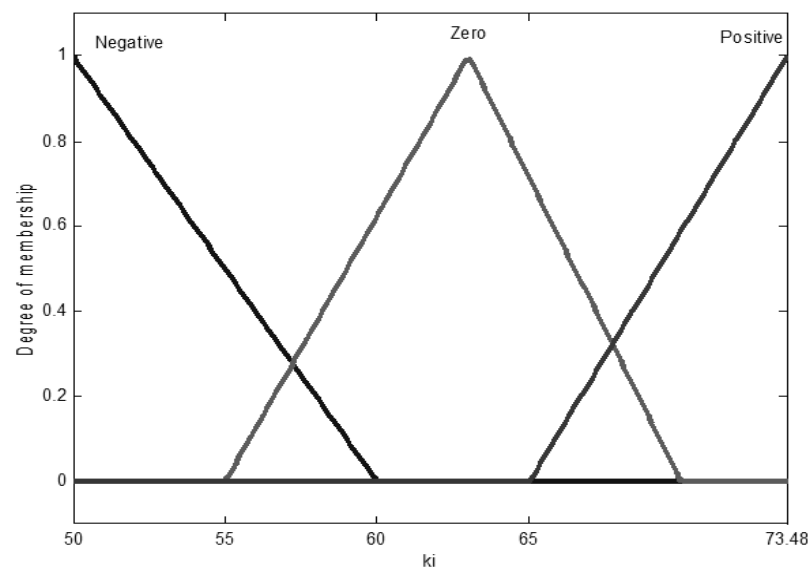

Fig. 14 Modified membership function of output variable kp by ICA 
Consequently, the response of the process under controlling of the Fuzzy-PI controller, in presence of the set point variations is depicted in fig. 16 .

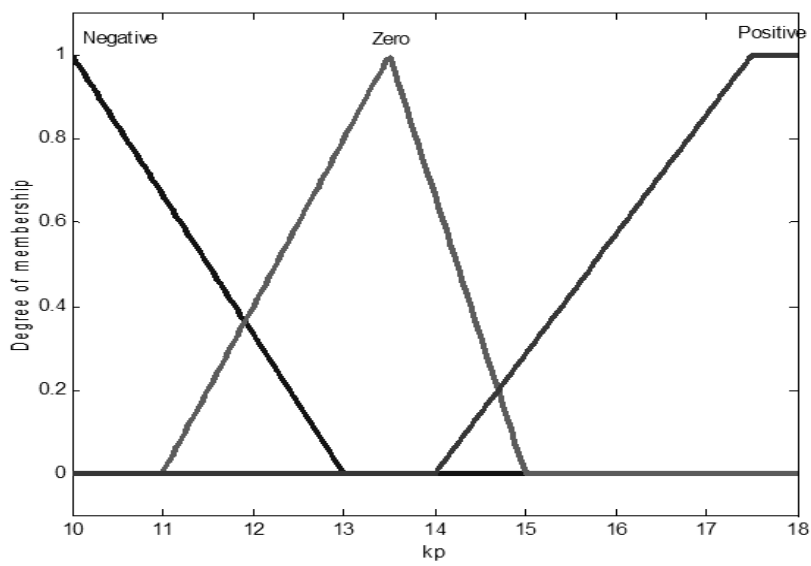

Fig. 15 Modified membership function of output variable ki by ICA

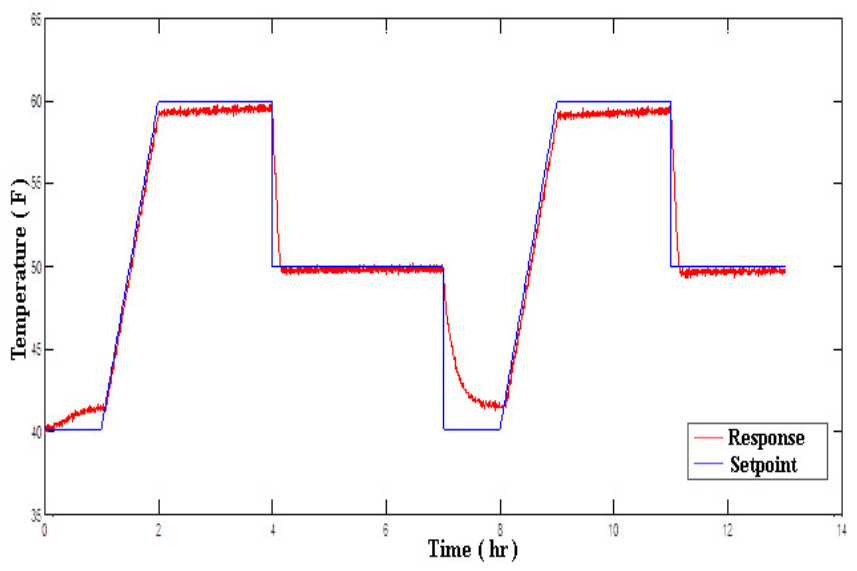

Fig. 16 Response of the system based on the Fuzzy-PI controller

\section{CONCLUSION}

In this study, a novel optimization algorithm named ICA is employed to achieve the optimum membership functions of fuzzy gain scheduling structure, which finally forms an intelligent Fuzzy-PI controller and then applied to the a chemical plant. The proposed controller was designed in such a way that the performance criterion is satisfied. Sum of square error was selected as the cost function. The designation tries to minimize the value of SSE. Furthermore, IAE was selected as the second criterion of performance checking. The problem of finding the optimum membership functions for inputs and outputs variables was consider in the form of optimization problem. To determine the evaluation of
FGS based on the ICA, two other controllers also were applied to the plant. The results show that the designed Fuzzy-PI controller presented high performance in controlling of the system. In addition, it is more robust than the conventional controllers in presence of the system's variations and encompassed the least aforementioned criteria of the set point tracking.

\section{REFERENCES}

[1] M.Delbari,K.Salahshoor,B.Moshiri,“Adaptive Generalized Predictive Control And Model Reference Adaptive Control For CSTR Reactor", International Conference on Intelligent Control and Information Processing, 2010.

[2] W.D.Chang , "Nonlinear System Identisication and Control using Real-Coded Genetic Algorith", Journal of Applied Mathematic and Modeling, vol 31,pp.541-550,2007.

[3] J.R.Jang, "ANFIS:Adaptive-Network-Based Fuzzy Inference System" IEEE Transaction on Systems,Man and Cybernetics,vol 23,pp.665-685,1993.

[4] R.Ketata , D.Geest, and A.Titli , “ Fuzzy Controller : Design, Evaluation, Parallel and Hierarchical Combination with a PID Controller", Journal of Fuzzy Sets and Systems, vol 71,pp. 113.

[5] A.MohammadZadeh, E.Atashpaz Gargari, C.Lucas, "Vehicle Fuzzy Controller Design Using Imperialist Competitive Algorithm", IEEE, World Congress on Computational Intelligence, 2008.

[6] Y. Yuan,H. Zhuang "AA Genetic Algorithm for Generating Fuzzy Classification Rules", Journal of Fuzzy Sets and Systems, Vol 84, pp.1-19,1996.

[7] E.Atashpaz-Gargari,C. Lucas, "Imperialist Competitive Algorithm: An Algorithm for Optimization Inspired by Imperialistic Competition”. IEEE ,CEC, Singapore, 2007.

[8] E.Atashpaz-Gargari, F. Hashemzadeh, and C. Lucas, "Designing MIMO PIID Controller using Colonial Competitive Algorithm: Applied to Distillation Column Process" IEEE, World Congress on Computational Intelligence, 2008.

[9] U. Sabura Banu, G. Uma, "Fuzzy Gain Scheduled Pole Placement Based State Feedback Control of CSTR" , International Conference on Information and Communication Technology in Electrical Science, 2007.

[10] U. Sabura Banu, G. Uma, "ANFIS Gain Scheduled CSTR with Genetic Algorithm Based PID Minimizing Integral Square Error", International Conference on Information and Communication Technology in Electrical Science,.2007.

[11] B. Wayne Bequette, "Process Dynamics: Modeling, Analysis and Simulation”, published by Prentice-Hall, 1998.

[12] M. Nikravesh ,A.E. Farell,T.G. Stanford , “ Control of nonisothermal CSTR with time varying parameters via dynamic neural network control (DNNC) ", Chemical Engineering Journal,vol 76,pp.1-16,2000.

[13] N. Jayakumar, M. Ali Hashim, and M. T. Thomas "Input Multiplicity Analysis in a Non-Isothermal CSTR for Acid-Catalyzed Hydrolysis of Acetic Anhydride", Chem. Eng. Technol,vol 33, pp. 499507,2010 .

[14] M.Ahmadi Movahed, A.M.Yazdani, "Application of Imperialist Competitive Algorithm in Online PI Controller ",IEEE, Second International Conference on Intelligent System, Modeling, and Simulation,2011. 